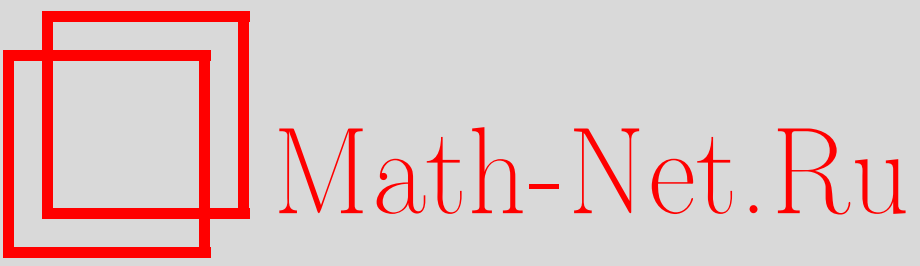

Д. И. Савельев, Замечание о связи линейного порядка с мерой и категорией, УМH, 1998, том 53, выпуск 6, 261-262

DOI: https://doi.org/10.4213/rm105

Использование Общероссийского математического портала Math-Net.Ru подразумевает, что вы прочитали и согласны с пользовательским соглашением

http://www . mathnet.ru/rus/agreement

Параметры загрузки:

IP : 54.92 .164 .108

26 апреля 2023 г., 14:55:56 


\title{
ЗАМЕЧАНИЕ О СВЯЗИ ЛИНЕЙНОГО ПОРЯДКА С МЕРОЙ И КАТЕГОРИЕЙ
}

\author{
Д. И. САВЕЛЬЕВ
}

Любое множество действительных чисел, измеримое по Лебегу и имеющее положительную меру или обладающее свойством Бэра и имеющее вторую категорию, содержит совершенное подмножество и, значит, имеет мощность континуума $c$.

Все ли множества мощности < с имеют нулевую меру Лебега и первую категорию?

Близкий вопрос поставлен еще в 1920 году Серпинским [1]. Эти и подобные вопросы о связи мощности с мерой и категорией неразрешимш в ZFC (теории Цермело-Френкеля с аксиомой выбора); работа Миллера [2] содержит весьма полный обзор моделей с соответствующими свойствами.

Мы рассмотрим один частньй вопрос о связи линейного порядка с мерой и категорией. Согласно Баумгартнеру [3] с ZFC совместна конъюнкция $\mathfrak{c}=\aleph_{2}$ со следующим обобщением теоремы Кантора:

(*) все неограниченные $\aleph_{1}$-плотные мнохсества действительных чисел подобнь (в порядковом смысле).

(Множество m-плотно в содержащем его множестве, если его пересечение с каждым открытым подмножеством последнего имеет мощность $\mathfrak{m}$; множество $\mathfrak{m}$-плотно, если оно $\mathfrak{m}$-плотно в себе.)

Покажем, что в модели Баумгартнера ответ на поставленньй вопрос положителен.

Теорема. Предположим (*). Тогда

(1) вьполняется "вторая континуум-гипотеза" Лузина $2^{\aleph_{1}}=\mathfrak{c}$;

(2) все множсества действительных чисел мощности $<\aleph_{2}$ имеют заведомо первую категорию и универсально нулевую меру;

(3) действительная прямая не содержит ни несчетных множеств Лузина, ни несчетных множеств Серпинского.

(Множество имеет заведомо первую категорию, если его пересечение с каждьм совершенным множеством имеет первую категорию в последнем; универсально нулевую меру, если оно имеет нулевую меру для каждой неатомарной борелевской меры, или, равносильно, если любой его гомеоморфный образ имеет нулевую меру Лебега. Множество есть множество Лузина (Серпинского), если любое его подмножество первой категории (нулевой меры Лебега) не более чем счетно.)

ДокаЗАтЕльство. (1) Всего $\aleph_{1}$-плотных множеств действительных чисел $2^{\aleph_{1}}$. Возьмем какое-нибудь одно, плотное на прямой, и отобразим его в остальные, сохраняя порядок. Продолжения этих отображений дадут $2^{\aleph_{1}}$ подобных отображений прямой в себя; между тем, последних всего $\mathfrak{c}$.

(Более слабое неравенство $\aleph_{1}<\mathfrak{c}$ можно получить из следующего резултата Серпинского [4]: существует $2^{\mathfrak{c}}$ порядковых типов мощности $\mathfrak{c}$.)

(2) Согласно Серпинскому [5, с. 247] существует множество действительных чисел мощности $\aleph_{1}$, любой обобщенно гомеоморфньй образ которого имеет заведомо первую категорию и нулевую меру Лебега.

(Отображение является обобщенным гомеоморфизмом, если оно взаимнооднозначно и измеримо по Борелю.)

Это множество можно считать $\aleph_{1}$-плотньм на прямой, иначе дополним его до такого, например, объединив его сдвиги на всевозможные рациональные расстояния. Взяв произвольное множество мощности $\aleph_{1}$ и, при необходимости, тоже дополнив его до $\aleph_{1}$-плотного на прямой, видим, что между ними существует подобное отображение и оно является гомеоморфным.

(3) немедленно следует из (2), 
Хорошо известно [6], что из аксиомы Мартина (даже из более слабой леммш Буса) следует, что все множества действительных чисел любой одинаковой бесконечной мощности $\mathfrak{m}<\mathfrak{c}$ обобщенно гомеоморфны, так как каждое подмножество такого множества является $F_{\sigma}$ в нем; из последнего свойства также легко получить $2^{\mathfrak{m}}=\mathfrak{c}$ и положительное решение нашего вопроса.

$\mathrm{C}$ другой стороны, конъюнкция аксиомы Мартина с отрицанием континуум-гипотезы не влечет $(*)$; это показали Аврахам и Шелах [7], ответив тем самым на вопрос Баумгартнера [3, с. 103].

Мне неизвестно, получен ли ответ на другой его вопрос: совместно ли с ZFC утверждение о подобии всех неограниченных $\aleph_{2}$-плотных множеств действительных чисел?

\section{СПИСОК ЛИТЕРАТУРЫ}

[1] Sierpinski W. // Fund. Math. 1920. V. 1. P. 224. [2] Miller A. W. // Trans. Amer. Math. Soc. 1981. V. 266. № 1. P. 93-114. [3] Baumgartner J. E. // Fund. Math. 1973. V. 79. P. 101-106. [4] Sierpinski W. // Fund. Math. 1950. V. 37. P. 253-264. [4] Sierpinski W. // Fund. Math. 1934. V. 22. P. 270-275. [5] Martin D. A., Solovay R. M. // Ann. Math. Logic. 1970. V. 2. P. 143-178. [7] Avraham U., Shelah S. // Israel J. Math. 1981. V. 38. P. 161-176.

Московский государственньй

Принято редколлегией университет им. М. В. Ломоносова

02.09 .1998 